\title{
Perda de nitrogênio por volatilização de amônia com o uso de dejetos de suínos em plantio direto(1)
}

\author{
Odair Port ${ }^{(2)}$, Celso Aita ${ }^{(3)}$ e Sandro José Giacomini(4)
}

\begin{abstract}
Resumo - O objetivo deste trabalho foi avaliar as perdas de $\mathrm{N}$ por volatilização de amônia com o uso de dejetos de suínos em sistema de plantio direto. No outono, a aplicação dos dejetos $\left(0,40\right.$ e $\left.80 \mathrm{~m}^{3} \mathrm{ha}^{-1}\right)$ foi feita sobre os resíduos culturais da vegetação espontânea e da aveia-preta remanescentes de cultivos anteriores. No verão, os dejetos também foram aplicados sobre os resíduos culturais dessas mesmas espécies, mas logo após serem manejados com rolo faca. Sobre os resíduos culturais da vegetação espontânea, a perda de $\mathrm{N}$ por volatilização de amônia chegou a $16,1 \%$ da quantidade de $\mathrm{N}$ amoniacal aplicada com os dejetos no outono e a $11,0 \%$ no verão. Sobre os resíduos culturais da aveia-preta, esses valores foram de $12,7 \%$ no outono e $6,5 \%$ no verão. As primeiras 20 horas após a aplicação dos dejetos foram responsáveis por aproximadamente $50 \%$ da perda total de nitrogênio. Os resultados deste trabalho evidenciam que, em sistema de plantio direto, o uso de dejetos de suínos sobre os resíduos culturais de aveia-preta reduz a emissão de amônia para a atmosfera, em relação aos resíduos culturais da vegetação espontânea do pousio invernal. Essa redução foi, em média, de 18,4\% no outono e $34,5 \%$ no verão.
\end{abstract}

Termos para indexação: poluição ambiental, resíduo de cultura, esterco líquido.

Nitrogen loss by ammonia volatilization with the use of pig slurry in no-till system

\begin{abstract}
The objective of this work was to evaluate the losses of $\mathrm{N}$ by ammonia volatilization with the use of pig slurry in no-till system. In the fall, the application of pig slurry $\left(0,40\right.$ and $\left.80 \mathrm{~m}^{3} \mathrm{ha}^{-1}\right)$ was on the residues of spontaneous vegetation and on the residues of black oat from the last cultivation. In the summer, the pig slurry was applied on the same residues, recently handled with roller knife blade. On the residues of spontaneous vegetation, the loss of $\mathrm{N}$ by ammonia volatilization reached $16.1 \%$ of the total ammoniacal $\mathrm{N}$ applied with the pig slurry at fall, and $11.0 \%$ at summer time. On the black oat residues these values were $12.7 \%$ in the fall and $6.5 \%$ in the summer. The first 20 hours after the pig slurry application were responsible for the approximately $50 \%$ of total $\mathrm{N}$ loss. The results of this work show that in no-till system the use of pig slurry on the black oat residues reduce the ammonia emission compared to the residues of winter spontaneous vegetation. This reduction was in average $18.4 \%$ in the fall and $34.5 \%$ in the summer.
\end{abstract}

Index terms: environmental pollution, crop residues, slurry.

\section{Introdução}

A utilização de dejetos de suínos como fertilizante é uma prática bastante difundida na Região Sul do

(1) Aceito para publicação em 15 de abril de 2003.

Extraído da dissertação de mestrado apresentada pelo primeiro autor à Universidade Federal de Santa Maria (UFSM), Santa Maria, RS. Financiada pela Fapergs e PRONEXCNPq/Finep.

(2) UFSM, Caixa Postal 221, CEP 97105-900 Santa Maria, RS. E-mail: a2060368@alunop.ufsm.br

(3) UFSM, Dep. de Solos. Bolsista do CNPq. E-mail: caita@ccr.ufsm.br

(4) UFSM. Bolsista da Capes. E-mail: sjgiacomini@mail.ufsm.br país. Nesse resíduo orgânico, o $\mathrm{N}$ apresenta-se, na maioria dos casos, em maior proporção na forma amoniacal $\left(\mathrm{NH}_{4}{ }^{+}+\mathrm{NH}_{3}\right)$, podendo chegar a $70 \%$ do $\mathrm{N}$ total (Scherer et al., 1996). Nessa forma, o N está suscetível a perdas, principalmente por volatilização da amônia, tanto nos locais de armazenamento dos dejetos (Sommer et al., 1993) como após a sua aplicação no campo (Al-Kanani et al., 1992; Rochette et al., 2001).

Perdas de N por volatilização de amônia, na faixa de $5 \%$ a $75 \%$ do $\mathrm{N}$ amoniacal dos dejetos, foram relatadas por Moal et al. (1995) e Sommer \& Hutchings (2001). Essa ampla variação nos valores encontrados se deve tanto às condições climáticas como às 
características físico-químicas dos dejetos e do solo. A concentração de $\mathrm{N}$ amoniacal e o $\mathrm{pH}$ constituem as principais características dos dejetos (Sommer \& Hutchings, 2001), enquanto a velocidade do vento, a temperatura, a umidade relativa do ar e a precipitação são as principais características climáticas. As principais características do solo são o pH, a taxa de infiltração de líquidos e o potencial de nitrificação do N aplicado (Whitehead, 1995; Sommer \& Hutcchings, 2001).

No Brasil, a maioria dos resultados de pesquisa envolvendo o uso de dejetos de suínos como fertilizante foi obtida com a aplicação deles em sistema de cultivo convencional. No sistema plantio direto, é necessário aplicar os dejetos sobre os resíduos culturais, tanto daqueles remanescentes das culturas comerciais como dos provenientes das plantas de cobertura de solo. Nesse sistema, em que os dejetos permanecem em contato com a atmosfera, deve aumentar o potencial de perdas de $\mathrm{N}$ por volatilização de amônia, em relação ao sistema de preparo convencional. Além disso, os próprios resíduos culturais contêm a enzima urease (Whitehead, 1995), o que aumenta a taxa de conversão da uréia dos dejetos em amônia.

A aplicação de dejetos sobre os resíduos culturais, especialmente de aveia, é uma prática bastante comum nas granjas produtoras de suínos. As conseqüências dessa prática sobre a nitrificação, a distribuição do nitrato no perfil do solo e a disponibilidade de $\mathrm{N}$ para o milho vêm sendo avaliadas em alguns estudos na Região Sul (Almeida, 2000). Todavia, a perda de $\mathrm{N}$ para a atmosfera, por volatilização de amônia com o uso dos dejetos em sistema de plantio direto, é um tema que deve ser melhor estudado, já que a intensidade desse processo pode afetar a eficiência dos dejetos como fertilizante nitrogenado e contribuir para a contaminação ambiental.

O objetivo deste trabalho foi avaliar as perdas de $\mathrm{N}$ por volatilização de amônia com o uso de dejetos de suínos em sistema de plantio direto.

\section{Material e Métodos}

O experimento foi realizado no campo, na área experimental do Departamento de Solos da Universidade Federal de Santa Maria, RS, em um solo classificado como Argissolo Vermelho distrófico arênico (Embrapa, 1999).
A avaliação das perdas de $\mathrm{N}$ por volatilização de amônia foi feita em duas épocas: uma no outono (junho de 2000) e outra no verão (fevereiro de 2001). Os tratamentos avaliados constaram de doses de dejetos de suínos (0, 40 e $80 \mathrm{~m}^{3} \mathrm{ha}^{-1}$ ) aplicados sobre os resíduos culturais de aveiapreta (Avena strigosa Schieb) e da vegetação espontânea da área. $\mathrm{O}$ delineamento experimental utilizado foi o de blocos casualizados com três repetições. No outono, os dejetos foram aplicados sobre os resíduos culturais da vegetação espontânea (pousio invernal) e da aveia-preta, remanescente de dois cultivos anteriores. No verão, os dejetos foram aplicados sobre os resíduos culturais da vegetação espontânea e da aveia-preta, logo após o manejo das espécies com rolo faca.

Os dejetos de suínos, com tempo de fermentação variando entre 1 e 60 dias, foram coletados na câmara de fermentação de uma bioesterqueira descoberta. Estes eram compostos de fezes, urina, sobras de alimentação e de água dos bebedouros, água das chuvas, pêlos e poeira.

Os atributos físicos e químicos analisados nos dejetos in natura, 24 horas após aplicação no campo, foram a matéria seca, o $\mathrm{pH}$ e os teores de $\mathrm{N}$ total e $\mathrm{N}$ amoniacal $\left(\mathrm{NH}_{4}{ }^{+}+\mathrm{NH}_{3}\right)$. A matéria seca foi determinada em estufa a $65^{\circ} \mathrm{C}$ mediante secagem de uma amostra de aproximadamente $60 \mathrm{~g}$ até peso constante e o $\mathrm{pH}$ em potenciômetro em uma alíquota de aproximadamente $80 \mathrm{~mL}$. Os valores de matéria seca e de $\mathrm{pH}$ dos dejetos foram, respectivamente, $2,83 \%$ e 7,5 na avaliação realizada no outono, e 5,23\% e 6,5 na do verão.

Os teores de $\mathrm{N}$ total $\mathrm{e} \mathrm{N}$ amoniacal foram determinados separadamente nas frações pastosa e líquida dos dejetos, conforme Scherer et al. (1996). O N total foi analisado a partir de digestão úmida dos dejetos, conforme Tedesco et al. (1995), porém sem o uso de água oxigenada na mistura de digestão, porque a água provoca a projeção e subida do material para fora dos tubos durante a fase inicial da digestão das amostras (Almeida, 2000). O N amoniacal foi determinado em destilador de arraste de vapores do tipo semimicro Kjeldahl, após adição de $20 \mathrm{~mL}$ de água destilada e 0,2 g de $\mathrm{MgO}$ em cada amostra (Sievers et al., 1984). As quantidades das diferentes formas de $\mathrm{N}$ presentes nas frações pastosa e líquida dos dejetos utilizados no outono e no verão encontram-se na Tabela 1 .

A avaliação das perdas de N por volatilização de amônia foi realizada conforme Nömmik (1973) com algumas adaptações. Foram utilizadas câmaras coletoras construídas a partir de tubos de PVC (cloro-polivinil) de $200 \mathrm{~mm}$ de diâmetro e $400 \mathrm{~mm}$ de altura, encaixadas sobre bases, também de PVC, com $185 \mathrm{~mm}$ de diâmetro e $70 \mathrm{~mm}$ de altura, as quais foram introduzidas no solo até uma profundidade de $30 \mathrm{~mm}$. Sobre os tubos foram encaixados suportes de 
metal aos quais foi acoplada uma tampa protetora (pratos de plástico), para impedir que a precipitação pluvial e os raios solares atingissem o sistema internamente.

Em cada câmara coletora foram colocadas duas esponjas tipo comercial de $20 \mathrm{~mm}$ de espessura e com densidade 28; a primeira a uma altura de $15 \mathrm{~cm}$ do solo, para captar a amônia volatilizada do solo, e a segunda a $30 \mathrm{~cm}$ de altura, para captar a amônia da atmosfera, impedindo a contaminação da esponja inferior. As esponjas eram mantidas sob suportes metálicos adaptados internamente nas câmaras coletoras. Elas foram embebidas com $100 \mathrm{~mL}$ de uma solução contendo ácido fosfórico $\left(50 \mathrm{~mL} \mathrm{~L}^{-1}\right)$ e glicerina $\left(40 \mathrm{~mL} \mathrm{~L}^{-1}\right)$. Antes de serem colocadas nas câmaras coletoras, as esponjas foram pressionadas manualmente para eliminar o excesso de solução de modo a evitar o gotejamento no interior dos cilindros. O volume final de solução retido em cada esponja era de aproximadamente $70 \mathrm{~mL}$.

Após cada coleta, o fosfato de amônio formado foi extraído das esponjas por meio de oito a dez lavagens sucessivas com solução de $\mathrm{KCl} 1 \mathrm{M}$. Após o ajuste do volume desta solução para $500 \mathrm{~mL}$, procedeu-se a destilação de uma alíquota de $20 \mathrm{~mL}$, em destilador de arraste de vapores, adicionando-se $5 \mathrm{~mL}$ de $\mathrm{NaOH} 10 \mathrm{~N}$ em cada amostra. No outono, as esponjas foram trocadas após 8 , $20,32,44,56,68$ e 73 horas do início do experimento, e no verão, após $8,21,32,44,56,69,79,92,103,116,128$, 137 e 157 horas.

No outono, a volatilização de amônia foi avaliada nos diferentes tratamentos colocando-se as bases dos coletores sobre os resíduos culturais da vegetação espontânea e da aveia-preta presentes na superfície do solo, remanescentes dos dois cultivos anteriores. Já no verão, os resíduos culturais de aveia-preta e vegetação espontânea foram colocados no interior das bases em quantidades equivalentes a 4,0 e $1,0 \mathrm{Mg} \mathrm{ha}^{-1}$ de matéria seca, respectivamente.
A aveia-preta foi coletada na fase de pleno florescimento e, após secada ao ar, foi cortada em pedaços de aproximadamente $16 \mathrm{~cm}$ de comprimento para ser colocada no interior das bases, no dia da aplicação dos dejetos. Esse procedimento foi adotado para simular a aplicação dos dejetos diretamente sobre os resíduos culturais da aveia-preta no campo, após manejo com rolo faca.

$\mathrm{Na}$ avaliação da interferência do coletor semi-aberto estático sobre as perdas de $\mathrm{N}$ por volatilização de amônia, foram instaladas bases que permaneceram abertas e que receberam os mesmos tratamentos das bases que foram cobertas pelas câmaras para a coleta da amônia volatilizada. Ao final das avaliações realizadas no outono ( 73 horas) e no verão ( 157 horas), determinaram-se os teores de $\mathrm{N}$ mineral $\left(\mathrm{N}\right.$ do $\mathrm{NH}_{4}{ }^{+} \mathrm{e}$ $\mathrm{N}$ do $\mathrm{NO}_{2}{ }^{-}+\mathrm{N}$ do $\mathrm{NO}_{3}{ }^{-}$) na camada de $0-5 \mathrm{~cm}$ do solo tanto nas bases cobertas com as câmaras coletoras como naquelas que permaneceram descobertas. Avaliou-se apenas o tratamento com resíduos culturais da vegetação espontânea (pousio). Em razão do curto tempo e da não ocorrência de chuvas durante as avaliações, considerou-se que todas as transformações do N, com exceção da volatilização de amônia, foram similares entre as bases cobertas e descobertas. A avaliação do $\mathrm{N}$ mineral no solo foi feita em destilador de arraste de vapores do tipo semimicro Kjeldahl (Tedesco et al., 1995).

Os resultados obtidos foram submetidos à análise de variância e as médias comparadas pelo teste de Tukey a 5\% de probabilidade.

\section{Resultados e Discussão}

\section{Perdas cumulativas de nitrogênio por volatilização de amônia}

As perdas de $\mathrm{N}$ por volatilização de amônia foram significativamente maiores nos tratamentos com o

Tabela 1. Quantidade das diferentes formas de $\mathrm{N}$ ( $\mathrm{N}$ total, $\mathrm{N}$ amoniacal e $\mathrm{N}$ orgânico) nas frações pastosa e líquida dos dejetos de suínos utilizados no outono e no verão e quantidades de $\mathrm{N}$ total, $\mathrm{N}$ amoniacal e $\mathrm{N}$ orgânico adicionadas com a dose de $40 \mathrm{~m}^{3} \mathrm{ha}^{-1(1)}$.

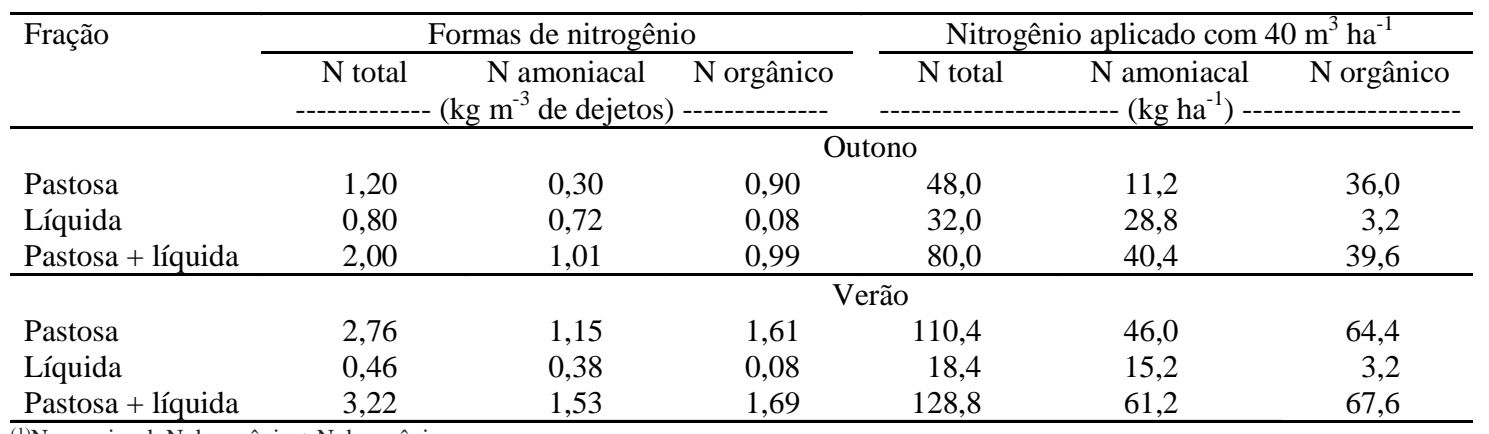


uso de dejetos, sendo proporcionais às doses aplicadas. No outono, as perdas acumuladas em 73 horas foram de $8,8 \mathrm{~kg} \mathrm{ha}^{-1} \mathrm{com}$ a aplicação de $40 \mathrm{~m}^{3} \mathrm{ha}^{-1}$ de dejetos sobre os resíduos culturais da vegetação espontânea (pousio) e 6,6 $\mathrm{kg} \mathrm{ha}^{-1} \mathrm{com}$ a aplicação sobre os resíduos culturais remanescentes de aveiapreta (Figura 1). Na dose de $80 \mathrm{~m}^{3} \mathrm{ha}^{-1}$, as perdas de $\mathrm{N}$ nesses mesmos tratamentos foram $12,1 \mathrm{e} 10,3 \mathrm{~kg} \mathrm{ha}^{-1}$, respectivamente. Já no verão, passadas 156 horas desde a aplicação dos dejetos, as perdas acumuladas de $\mathrm{N}$ na dose de $40 \mathrm{~m}^{3} \mathrm{ha}^{-1}$ totalizaram $9,4 \mathrm{~kg} \mathrm{ha}^{-1}$ no pousio e $5,9 \mathrm{~kg} \mathrm{ha}^{-1}$ na aveia-preta (Figura 1). Com a dose de $80 \mathrm{~m}^{3} \mathrm{ha}^{-1}$ esses valores aumentaram para 15,0 e 10,6 $\mathrm{kg} \mathrm{ha}^{-1}$, nos mesmos tratamentos.

As perdas de $\mathrm{N}$ amoniacal dos dejetos, calculadas considerando-se as quantidades de $\mathrm{N}$ amoniacal aplicadas (Tabela 1) e a volatilização cumulativa de amônia, nos tratamentos com e sem dejetos (Figu-
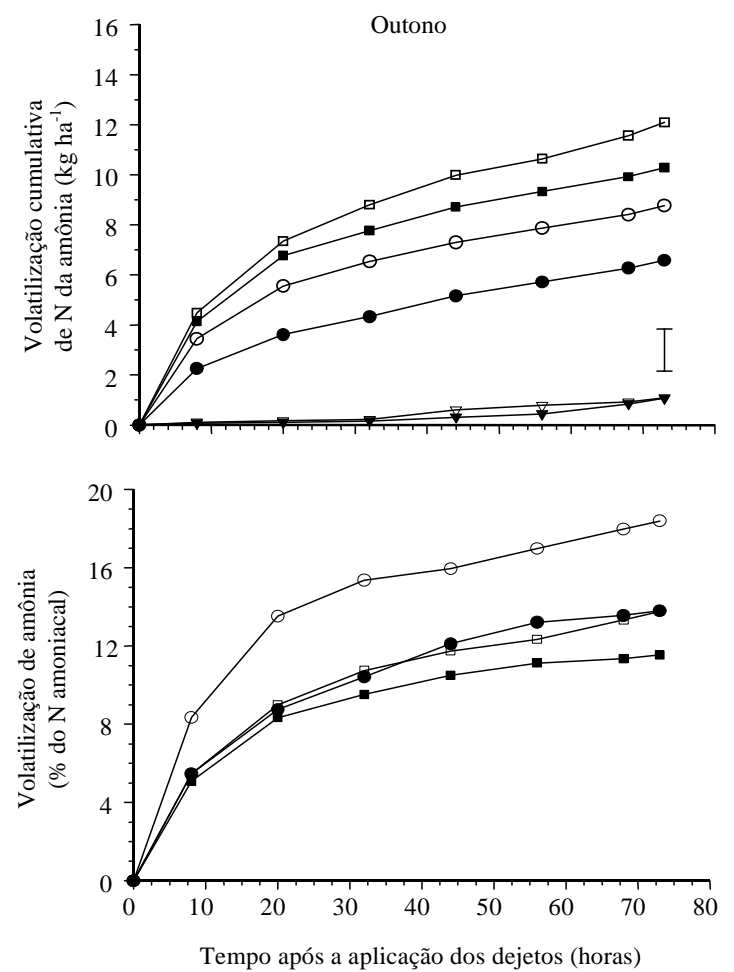

ra 1), indicam que, no outono, $18,4 \%$ e $13,7 \%$ do $\mathrm{N}$ amoniacal aplicado nas doses de $40 \mathrm{e}$ de $80 \mathrm{~m}^{3} \mathrm{ha}^{-1}$ sobre os resíduos culturais da vegetação espontânea do pousio foram perdidos por volatilização de amônia, respectivamente. Sobre os resíduos culturais remanescentes da aveia-preta, esses valores diminuíram para $13,8 \%$ e $11,5 \%$.

No verão, a proporção do $\mathrm{N}$ amoniacal dos dejetos perdida por volatilização de amônia foi menor do que no outono. Mesmo aumentando o tempo de avaliação de 73 para 153 horas, a perda média com as doses de 40 e $80 \mathrm{~m}^{3} \mathrm{ha}^{-1}$ foi de $11 \%$ do $\mathrm{N}$ amoniacal aplicando os dejetos sobre os resíduos culturais da vegetação espontânea e 6,5\%, sobre os resíduos culturais da aveia-preta (Figura 1).

As perdas de $\mathrm{N}$ por volatilização de amônia com o uso de dejetos de suínos é bastante variável, ou seja,
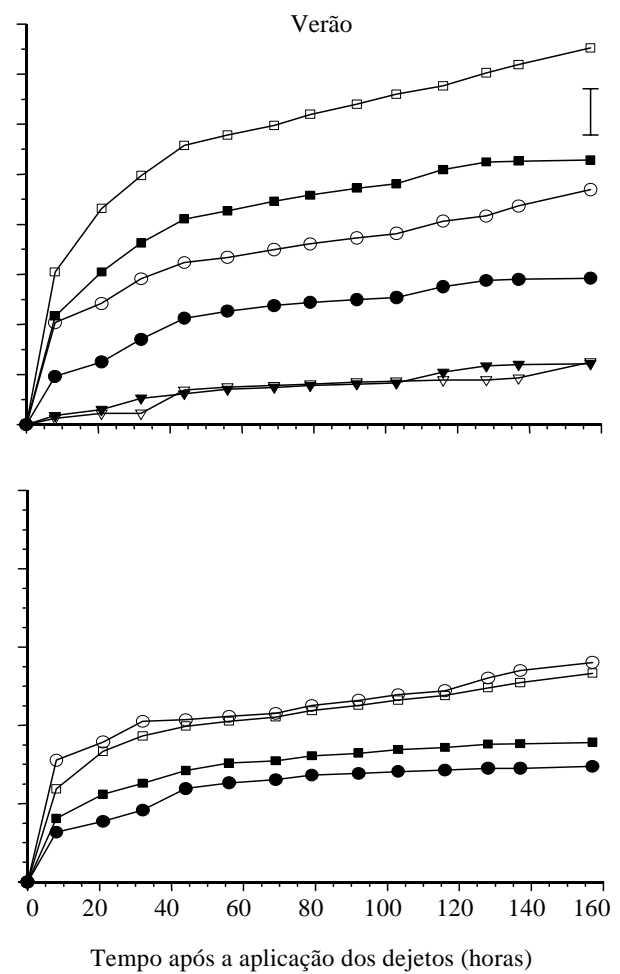

Figura 1. Perdas acumuladas de $\mathrm{N}$ por volatilização de amônia em $\mathrm{kg} \mathrm{ha}^{-1}$ e em porcentagem do $\mathrm{N}$ amoniacal aplicado nas doses de dejetos sobre os resíduos remanescentes da vegetação espontânea (pousio) $\left(\nabla: 0\right.$; ०: 40; $\square: 80 \mathrm{~m}^{3}$ ha $^{-1}$ ) e da aveia-preta $\left(\mathbf{\nabla}: 0 ; \bullet: 40 ; \mathbf{\square}: 80 \mathrm{~m}^{3} \mathrm{ha}^{-1}\right)$, no outono e no verão. A barra vertical indica diferença mínima significativa pelo teste de Tukey a $5 \%$ de probabilidade. 
de $5 \%$ até $75 \%$ do $\mathrm{N}$ amoniacal (Moal et al., 1995). Essa ampla variação nos valores de volatilização de amônia é causada por inúmeros fatores, principalmente pela composição físico-química dos dejetos e do solo, além das condições climáticas predominantes em cada situação (Sommer \& Hutchings, 2001).

Outro fator que pode contribuir para os diferentes índices de perdas de $\mathrm{N}$ encontrados envolve os métodos empregados na sua quantificação. Moal et al. (1995) utilizaram túneis com circulação de ar e captação da amônia volatilizada em solução de ácido bórico. Na dose de $40 \mathrm{~m}^{3} \mathrm{ha}^{-1}$ de dejetos de suínos (319 $\mathrm{kg} \mathrm{ha}^{-1}$ de $\mathrm{N}$ amoniacal) com 19,1\% de matéria seca e temperatura variando entre $4^{\circ} \mathrm{C}$ e $20^{\circ} \mathrm{C}$, os autores encontraram, sobre a resteva de trigo, perdas de $131 \mathrm{~kg} \mathrm{ha}^{-1}$ de N (41\% do N amoniacal aplicado). Utilizando esse mesmo método, Sommer et al. (1997) verificaram que $25,3 \%$ dos $60 \mathrm{~kg} \mathrm{ha}^{-1}$ de $\mathrm{N}$ amoniacal aplicados com os dejetos de suínos em área cultivada com trigo foram perdidos a uma temperatura média de $9^{\circ} \mathrm{C}$.

A comparação desses valores de perda de $\mathrm{N}$ amoniacal aos obtidos no presente trabalho permite inferir que o dispositivo em que há circulação de ar é mais eficiente em captar a amônia volatilizada do que o dispositivo semi-aberto estático, o qual permanece isolado da ação do vento durante o período de avaliação e, por isso, pode subestimar a perda real de $\mathrm{N}$ por volatilização de amônia. Thompson et al. (1990) e Sommer \& Hutchings (2001) verificaram que há uma relação direta entre taxas de perdas de amônia e velocidade do vento, a qual afeta a atmosfera imediatamente acima da região onde os dejetos foram aplicados, aumentando a taxa de difusão de amônia para a atmosfera.

A proporção de $\mathrm{N}$ amoniacal nos dejetos de suínos bem como os valores da matéria seca deles podem afetar as taxas de volatilização de amônia (Sommer \& Hutchings, 2001), havendo, normalmente, uma relação direta entre esses dois atributos e as perdas de N (Moal et al., 1995). Tanto nos dejetos aplicados no outono como no verão, a proporção de $\mathrm{N}$ amoniacal era de aproximadamente 50\% (Tabela 1), e as quantidades aplicadas foram de 40,0 e 61,2 $\mathrm{kg} \mathrm{ha}^{-1}$ de $\mathrm{N}$ amoniacal, respectivamente. Esses valores representam, em média, apenas $16 \%$ da quantidade de $\mathrm{N}$ amoniacal aplicada por Moal et al. (1995), e podem ser outra causa das menores perdas de amônia encontradas no presente trabalho.

Apesar de os dejetos aplicados no verão apresentarem maior valor de matéria seca do que os aplicados no outono $(5,23 \%$ contra $2,83 \%)$, as perdas de amônia mostraram comportamento inverso, ou seja, foram proporcionalmente maiores no outono do que no verão (Figura 1). Esse comportamento deve estar relacionado aos valores de $\mathrm{pH}$ dos dejetos já que as perdas de amônia são fortemente influenciadas por este atributo (Al-Kanani et al., 1992), cujo valor foi de 7,5 no outono e de 6,5 no verão. Isto porque nos dejetos de animais a forma iônica $\left(\mathrm{NH}_{4}{ }^{+}\right)$e a forma gasosa $\left(\mathrm{NH}_{3}\right)$, que é volátil, encontram-se em equilíbrio (Kirchmann \& Witter, 1989) e a predominância de uma forma sobre a outra depende do $\mathrm{pH}$. A proporção de amônia, que é de apenas 0,09\% a pH 6,02 (Kirchmann \& Witter, 1989), pode aumentar para 7\% a pH 7,5 (Scherer et al., 1996) e para 50\% a pH 9,3 (Kirchmann \& Witter, 1989).

\section{Taxa de volatilização de amônia para a atmosfera}

A taxa de volatilização de amônia foi calculada dividindo-se a quantidade de $\mathrm{N}$ amoniacal pelo intervalo de tempo entre as avaliações. Tanto no outono como no verão, a cinética de volatilização de amônia foi similar, com as maiores taxas de emissão ocorrendo nas primeiras horas após a aplicação dos dejetos (Figura 2). Após 20 horas, o fluxo de amônia diminuiu sensivelmente com pequenas diferenças entre tratamentos.

A diminuição das perdas de amônia da primeira avaliação realizada (oito horas) para a segunda avaliação (20 horas) foi mais gradual no experimento realizado no outono do que no verão (Figura 2). Isto se deve, provavelmente, aos menores valores de temperatura verificados no outono (média diária de $8,2^{\circ} \mathrm{C}$ ) em relação ao verão (média diária de $25,1^{\circ} \mathrm{C}$ ).

Essa cinética de volatilização de amônia, com perdas mais acentuadas logo após a aplicação dos dejetos, é mencionada em diversos trabalhos tanto com dejetos de suínos como de bovinos. Assim, nas 24 horas seguintes à aplicação dos dejetos ocorreram perdas de $57 \%$ a $77 \%$ (Thompson et al., 1990) e de 59\% (Chadwick et al., 1998) do total de N perdido por volatilização de amônia. Rochette et al. (2001) 
verificaram que $60 \%$ da emissão total de amônia ocorreu nas primeiras 11 horas após a aplicação de dejetos de suínos sobre os resíduos culturais de colza. Tais resultados evidenciam a importância de se considerar as condições edafoclimáticas quando aplicar os dejetos no campo. Provavelmente aplicações de dejetos ao final do dia e em solos úmidos reduzam a emissão de amônia para a atmosfera.

\section{Efeito dos resíduos culturais da aveia-preta na volatilização de amônia}

O tratamento em que os dejetos foram aplicados sobre os resíduos culturais de aveia-preta propiciou diminuição nas perdas por volatilização de amônia em relação à aplicação sobre os resíduos culturais da vegetação espontânea. No outono, quando a aplicação foi feita sobre os resíduos culturais de aveiapreta remanescentes de anos anteriores, a redução das perdas durante o período avaliado foi de $22 \%$ na dose de $40 \mathrm{~m}^{3} \mathrm{ha}^{-1}$ e de $15 \%$ na dose de $80 \mathrm{~m}^{3} \mathrm{ha}^{-1}$ (Figura 1). No verão, com os dejetos aplicados sobre os resíduos culturais da aveia-preta logo após o seu manejo com rolo faca, o efeito dos resíduos culturais, diminuindo as perdas de $\mathrm{N}$ por volatização de amônia, foi ainda mais evidente do que no outono (Figura 1). Nessa situação, a volatilização de amônia foi inferior à do tratamento em que os dejetos foram aplicados sobre uma quantidade menor de resíduos culturais provenientes da vegetação espontânea do pousio. A redução das perdas foi de $39 \%$ na dose de $40 \mathrm{~m}^{3} \mathrm{ha}^{-1}$ e de $30 \%$ na dose de $80 \mathrm{~m}^{3} \mathrm{ha}^{-1}$.

A redução na volatilização de amônia proporcionada pelos resíduos culturais da aveia-preta pode ter sido condicionada por diversos fatores. À medida que a palha permanece na superfície do solo há a formação de um microclima ao qual é vinculada, normalmente, diminuição na temperatura e aumento na umidade do solo em relação ao solo descoberto.

Além de afetar a temperatura do solo, a palha de aveia-preta pode ter retido fisicamente $\mathrm{N}$ na forma amoniacal, especialmente aquele presente na fração líquida dos dejetos. Como os resíduos culturais da aveia-preta recém-manejada devem apresentar maior capacidade de retenção da fração líquida do que os da aveia-preta remanescente de anos anteriores, o efeito da palha na diminuição da volatilização de amônia, em relação ao pousio, foi maior no verão do que no outono (Figura 1).

A composição do material orgânico sobre o qual os dejetos são adicionados também pode exercer influência na taxa de volatilização de nitrogênio. Em laboratório, Kirchmann \& Witter (1989) aplicando dejetos de aves sobre a palha de aveia com relação C/N variando entre 18 e 36, e Subair et al. (1999)
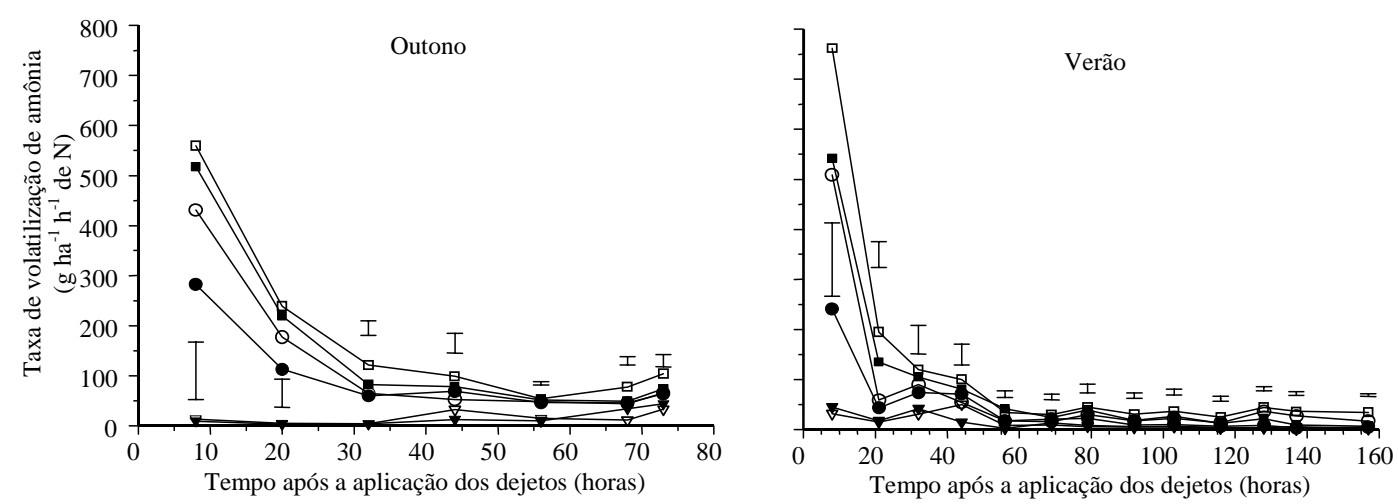

Figura 2. Taxa de emissão de $\mathrm{N}$ amoniacal para a atmosfera em cada avaliação durante o período de outono e de verão nas diferentes doses de dejetos aplicadas sobre os resíduos remanescentes da vegetação espontânea (pousio) ( $\nabla: 0$; ○: 40; $\left.\square: 80 \mathrm{~m}^{3} \mathrm{ha}^{-1}\right)$ e da aveia-preta $\left(\boldsymbol{\nabla}: 0 ; \bullet: 40 ; \mathbf{\square}: 80 \mathrm{~m}^{3} \mathrm{ha}^{-1}\right)$. Barras verticais indicam diferença mínima significativa pelo teste de Tukey a $5 \%$ de probabilidade. 
aplicando os dejetos sobre papel com $\mathrm{C} / \mathrm{N}$ entre 35,6 e 44,9, constataram menores perdas de $\mathrm{N}$ à medida que a relação $\mathrm{C} / \mathrm{N}$ aumentou. Tais resultados foram atribuídos à imobilização microbiana do $\mathrm{N}$ mineral dos dejetos pela população decompositora da fração carbonada dos materiais orgânicos, diminuindo assim a quantidade de $\mathrm{N}$ suscetível a perdas por volatilização de amônia.

\section{Interferência do coletor semi-aberto estático nas perdas de nitrogênio por volatilização de amônia}

$\mathrm{Na}$ avaliação realizada no outono, a quantidade de $\mathrm{N}$ amoniacal na camada $0-5 \mathrm{~cm}$ do solo do tratamento em pousio, na dose de $80 \mathrm{~m}^{3} \mathrm{ha}^{-1}$, foi $34 \%$ menor nas bases que permaneceram descobertas em relação às cobertas pela câmara coletora da amônia volatilizada (Tabela 2 ).

As quantidades de $\mathrm{N}$ nítrico encontradas na camada de $0-5 \mathrm{~cm}$ não diferiram entre as bases que permaneceram cobertas e as descobertas, e os baixos valores de $\mathrm{N}$ nítrico indicam que a taxa de nitrificação foi pequena durante o período de avaliação da volatilização de amônia. Como não ocorreram chuvas nesse período e a avaliação foi feita no tratamento em pousio, com baixa disponibilidade de $\mathrm{C}$ facilmente oxidável, pode-se considerar como insignificantes as saídas de $\mathrm{N}$ do sistema via lixiviação de nitrato e desnitrificação. Assumindo ainda que a imo- bilização microbiana de $\mathrm{N}$ tenha sido similar entre as bases cobertas e as descobertas, é possível atribuir como principal causa das diferenças observadas nas quantidades de $\mathrm{N}$ amoniacal as perdas diferenciadas de $\mathrm{N}$ entre os dois sistemas via volatilização de amônia. Portanto, o dispositivo utilizado teria subestimado as perdas de amônia em $24,1 \%$ no outono, na média das doses de 40 e $80 \mathrm{~m}^{3} \mathrm{ha}^{-1}$.

No verão, a comparação das quantidades de $\mathrm{N}$ mineral do solo entre as bases cobertas e descobertas não pode ser feita apenas a partir dos valores de $\mathrm{N}$ amoniacal, já que essa forma de $\mathrm{N}$ foi rapidamente oxidada para nitrato (Tabela 2). As quantidades de $\mathrm{N}$ nítrico nas bases que permaneceram cobertas foram praticamente duas vezes maiores do que as encontradas nas bases descobertas. É provável que a maior umidade de solo nessa condição tenha contribuído para o aumento na taxa de nitrificação do $\mathrm{N}$ amoniacal dos dejetos (Tabela 2).

Comparando as quantidades de $\mathrm{N}$ mineral $\left(\mathrm{NH}_{4}{ }^{+}+\right.$ $\mathrm{NO}_{3}{ }^{-}$), observa-se que nas bases mantidas cobertas para a avaliação da amônia volatilizada elas foram superiores às bases descobertas em 30,3\%, na média das doses de 40 e $80 \mathrm{~m}^{3}$ ha $^{-1}$ (Tabela 2).

A subestimativa das perdas de $\mathrm{N}$ por volatilização de amônia de 27,2\%, na média das avaliações de outono e verão, é próxima da encontrada por Lara Cabezas \& Trivelin (1990) ao aplicarem uréia marcada com ${ }^{15} \mathrm{~N}$ no solo e medirem a volatilização de amônia utilizando um sistema coletor semi-aberto estático

Tabela 2. Quantidades de $\mathrm{N}$ mineral e umidade na camada de 0-5 cm do solo das bases das câmaras coletoras de amônia que permaneceram descobertas e das bases que permaneceram cobertas pelos coletores, ao final das avaliações efetuadas no outono e no verão, no sistema em que os dejetos foram aplicados sobre os resíduos remanescentes da vegetação espontânea (pousio) ${ }^{(1)}$.

\begin{tabular}{|c|c|c|c|c|c|c|c|c|}
\hline \multirow{3}{*}{$\frac{\text { Dejetos }}{\left(\mathrm{m}^{3} \mathrm{ha}^{-1}\right)}$} & \multicolumn{2}{|c|}{$\mathrm{N}$ do $\mathrm{NH}_{4}{ }^{+}$} & \multicolumn{2}{|c|}{$\mathrm{N}$ do $\mathrm{NO}_{3}^{-}$} & \multicolumn{2}{|c|}{$\mathrm{N}$ do $\mathrm{NH}_{4}^{+}+\mathrm{N}$ do $\mathrm{NO}_{3}^{-}$} & \multicolumn{2}{|c|}{ Umidade do solo } \\
\hline & Descoberta & Coberta & Descoberta & Coberta & Descoberta & Coberta & Descoberta & Coberta \\
\hline & \multicolumn{4}{|c|}{ - $\left(\mathrm{kg} \mathrm{ha}^{-1}\right)^{-}$} & & ---- & \multicolumn{2}{|c|}{ - } \\
\hline \multicolumn{9}{|c|}{ Outono } \\
\hline 40 & $47,8 \mathrm{a}$ & $54,4 \mathrm{a}$ & $4,5 \mathrm{a}$ & $6,5 \mathrm{a}$ & $52,3 \mathrm{a}$ & $60,9 \mathrm{a}$ & 13,4 & 17,9 \\
\hline 80 & $62,7 \mathrm{~b}$ & $84,3 \mathrm{a}$ & $6,8 \mathrm{a}$ & $7,9 \mathrm{a}$ & $69,5 \mathrm{~b}$ & $92,2 \mathrm{a}$ & 16,7 & 20,3 \\
\hline \multicolumn{9}{|c|}{ Verão } \\
\hline 0 & $1,5 \mathrm{~b}$ & $2,8 \mathrm{a}$ & $13,1 \mathrm{a}$ & $13,9 \mathrm{a}$ & $14,6 \mathrm{a}$ & $16,7 \mathrm{a}$ & 21,0 & 27,0 \\
\hline 40 & $13,7 \mathrm{~b}$ & $15,7 \mathrm{a}$ & $17,6 \mathrm{~b}$ & $30,4 \mathrm{a}$ & $31,3 b$ & $46,1 \mathrm{a}$ & 19,2 & 25,6 \\
\hline 80 & $44,7 \mathrm{a}$ & $35,6 b$ & $18,6 \mathrm{~b}$ & $36,2 \mathrm{a}$ & $63,3 \mathrm{~b}$ & $71,8 \mathrm{a}$ & 18,9 & 27,8 \\
\hline
\end{tabular}

${ }^{(1)}$ Médias seguidas da mesma letra, na coluna, não diferem entre si pelo teste de Tukey a $5 \%$ de probabilidade. 
semelhante ao do presente trabalho. Ao final de 37 dias, os autores coletaram amostras de solo nos tratamentos com e sem coletor e, utilizando o método do balanço isotópico de ${ }^{15} \mathrm{~N}$, verificaram que, na presença da câmara coletora, houve redução na volatilização de amônia proveniente da uréia de $29 \%$, em relação ao tratamento sem câmara coletora.

A interferência do coletor semi-aberto estático diminuindo a volatilização de amônia se deve a alterações provocadas no ambiente da atmosfera acima da superfície do solo (Lara Cabezas \& Trivelin, 1990). A ausência de circulação de ar provocaria apreciável diminuição da evaporação de água do solo sob a influência da câmara coletora. De fato, os valores obtidos nas bases com câmara coletora foram, em média, 33\% maiores que os das bases abertas (Tabela 2). Isso sugere a reciclagem da água evaporada do solo, ou seja, ela retorna pelas paredes da câmara com parte da amônia volatilizada.

Apesar de subestimar as perdas reais de amônia, o coletor semi-aberto estático parece ser adequado para comparação de tratamentos em condições idênticas de solo e de clima. No presente trabalho, por exemplo, foi possível constatar que, em sistema plantio direto, o uso de dejetos de suínos sobre os resíduos culturais de aveia-preta resulta em menores perdas de N para a atmosfera por volatilização de amônia do que o uso dos dejetos sobre os resíduos culturais da vegetação espontânea do pousio invernal.

\section{Conclusões}

1. A aplicação dos dejetos de suínos em sistema de plantio direto, na presença de maiores quantidades de resíduos culturais de aveia-preta em relação à vegetação espontânea do pousio, reduz a emissão de amônia para a atmosfera.

2. A maior parte das perdas de $\mathrm{N}$ por volatilização de amônia ocorrem nas primeiras horas após a aplicação dos dejetos no campo.

3. Apesar do dispositivo semi-aberto estático subestimar as perdas reais de $\mathrm{N}$ por volatilização de amônia ele é útil na comparação de tratamentos.

\section{Referências}

AL KANANI, T.; AKOCHI, E.; MACKENZIE, A. F.; ALLI, I.; BARRINGTON, S. Organic and inorganic amendments to reduce ammonia losses from liquid hog manure. Journal of Environmental Quality, Madison, v. 21, n. 4, p. 709-715, 1992.

ALMEIDA, A. C. R. Uso associado de esterco líquido de suínos e plantas de cobertura de solo na cultura do milho. 2000. 114 f. Dissertação (Mestrado em Agronomia) - Universidade Federal de Santa Maria, Santa Maria, 2000.

CHADWICK, D. R.; WEERDEN, T.; MARTINEZ, J.; PAIN, B. F. Nitrogen transformations and losses following pig slurry applications to a natural soil filter system (Solepur process) in Brittany, France. Journal of Agricultural Engineering Research, London, v. 69, n. 1, p. 85-93, 1998.

EMBRAPA. Centro Nacional de Pesquisa de Solos (Rio de Janeiro, RJ). Sistema brasileiro de classificação de solos. Brasília: Embrapa-SPI/Embrapa-CNPS, 1999. 412 p.

KIRCHMANN, H.; WITTER, E. Ammonia volatilization during aerobic and anaerobic decomposition. Plant and Soil, Dordrecht, v. 115, n. 1, p. 35-41, 1989.

LARA CABEZAS, W. A. R.; TRIVELIN, P. C. O. Eficiência de um coletor semi-aberto estático na quantificação de $\mathrm{N}_{-} \mathrm{NH}_{3}$ volatilizado da uréia aplicada ao solo. Revista Brasileira de Ciência do Solo, Campinas, v. 14, n. 3, p. 345-352, 1990.

MOAL, J. F.; MARTINEZ, J.; GUIZIOU, F.; COSTE, C. M. Ammonia volatilization following surface applied pig and cattle slurry in France. Journal of Agricultural Science, Cambridge, Inglaterra, v. 125, n. 2, p. 245-252, 1995.

NÖMMIK, H. The effect of pellet size on the ammonia loss from urea applied to forest. Plant and Soil, Dordrecht, v. 39, n. 2, p. 309-318, 1973.

ROCHETTE, P.; CHANTIGNY, M. H.; ANGERS, D. A.; BERTRAND, N.; CÔTÉ, D. Ammonia volatilization and soil nitrogen dynamics following fall application of pig slurry on canola crop residues. Canadian Journal of Soil Science, Ottawa, v. 81, n. 3, p. 515-523, 2001. 
SCHERER, E. E.; AITA, C.; BALDISSERA, I. T. Avaliação da qualidade do esterco líquido de suínos da região oeste catarinense para fins de utilização como fertilizante. Florianópolis: Epagri, 1996. 46 p. (Boletim Técnico, 79).

SIEVERS, D. M.; DOYLE, K.; PORTER, J. H. Ammonia measurement in high organic wastes. Transactions of the ASAE, St. Joseph, v. 27, n. 3, p. 182-184, 1984.

SOMMER, S. G.; CHRISTENSEN, B. T.; NIELSEN, N. E.; SCHJØRRING, J. K. Ammonia volatilization during storage of cattle and pig slurry: effect of surface cover. Journal of Agricultural Science, Cambridge, Inglaterra, v. 121, n. 1 , p. 63-71, 1993.

SOMMER, S. G.; FRIIS, E.; BACH, A.; SCHJØRRING, J. K. Ammonia volatilization from pig slurry applied with trail hoses or broadspread to winter wheat: effects of developmental stage, microclimate, and leaf ammonia absorption. Journal of Environmental Quality, Madison, v. 26, n. 4, p. 1153-1160, 1997.

SOMMER, S. G.; HUTCHINGS, N. J. Ammonia emission from field applied manure and its reduction: invited paper.
European Journal of Agronomy, Amsterdam, v. 15, n. 1, p. 1-15, 2001.

SUBAIR, S.; FYLES, J. W.; O'HALLORAN, I. P. Ammonia volatilization from liquid hog manure amended with paper products in the laboratory. Journal of Environmental Quality, Madison, v. 28, n. 1, p. 202207, 1999.

TEDESCO, M. J.; GIANELLO, C.; BISSANI, C. A.; BOHNEN, H.; VOLKWEISS, S. J. Análises de solo, plantas e outros materiais. Porto Alegre: UFRGS, 1995. 174 p. (Boletim Técnico, 5).

THOMPSON, R. B.; PAIN, B. F.; LOCKYER, D. R. Ammonia volatilization from cattle slurry following surface application to grassland - II: influence of application rate, wind speed and applying slurry in narrow bands. Plant and Soil, Dordrecht, v. 125, n. 1, p. 119-128, 1990.

WHITEHEAD, D. C. Grassland nitrogen. Wallingford: CAB International, 1995. 352 p. 